namely, (a) the willing agreement among all technical writers to use the word weight to designate the earth pull on a body, followed by (b) a careless reversion to the usage of the coal man and the acceptance of his meaning when he sends a bill for 2,000 pounds weight of coal! Let it be understood that the coal man's weight is precisely the physicist's and the chemist's mass. The balance scale measures mass, it does not and can not measure force in any precise sense until the ratio of the local value of gravity to the value of gravity in London is known.

WM. S. FrankLin, BarRy MacNutT

\section{THE CANONS OF COMPARATIVE ANATOMY}

IN a recent number of Science ${ }^{1}$ Professor W. P. Thompson refers to a recent letter of mine to that journal. He maintains that the assertion on my part that he made use of the Canons of Comparative Anatomy through ignorance to reach an erroneous conclusion is inaccurate. This seems to be contrary to the facts, since Professor Thompson on his own showing is culpable either of inexcusable ignorance or deliberate misrepresentation. $\mathrm{He}$ emphasizes the value of the genus Vaccinium as a type illustrative of the relations between two main forms of vessel in the angiosperms, namely, the one with scalariform perforations and that with porous perforations. Had his acquaintance with the anatomy of Vaccinium been more complete, he would have realized that the type of vessel found in the Gnetalian genus Ephedra is also present there. Contrary to Mr. Thompson's statement, moreover, vessels of the Gnetum type prevail in the higher angiosperms rather than in the lower ones, being universal, for example, in the Compositæ and extremely common in the monocotyledons. It is unfortunate that Professor Thompson either through ignorance or intention has failed to emphasize the presence of the Gnetum type of vessel in the angiosperms, particularly as in many cases it has in that large group a mode of origin similar to that described by him in the case of Gnetum. It thus appears

\footnotetext{
1 N. S., Vol. XLVII., No. 1221.
}

that his contention that the Gnetum and Ephedra types of vessels are fundamentally different in origin from those of the angiosperms is without foundation in fact, since both these types are actually present in quite high angiosperms. Professor Thompson's attitude is further highly inconsistent, since in earlier publication he has called attention to the resemblances between the wood rays of Ephedra and those of certain angiosperms, and to the occurrence of nuclear fusions in Gnetum which he compares with that found in the case of the endosperm nucleus of the angiosperms. E. C. JEFFREY

\section{WHOLE-WHEAT BREAD}

To the Editor of Science: As a contribution to the discussion "Shall We Eat Whole-wheat Bread,"1 may I quote from the findings of a special committee appointed by the Royal Society of England, to study this matter, ${ }^{2}$ as follows:

The bread now in use is prepared from grain milled to 90 per cent. with the addition of other. cereals. After investigation, a committee of the Royal Society has issued a report on the following questions: (1) What gain, if any, in food value accrues from a rise in the milling standard from 80 to 90 per cent., and does the dilution of wheat flour with other cereals modify the food value of the bread? (2) What would be the effect on the health of the consumption of such breads? (3) How far would such breads prove acceptable? Experiments were made with wheat flour, extracted to 80 and to 90 per cent. The analytical work was done in the biochemical department of the University of Cambridge and in the physiological laboratories of the universities of Glasgow and London. The diet consisted of $800 \mathrm{gm}$. of bread with butter, cheese, minced or potted meat, fruit jelly, milk and sugar, tea or coffee, and in one case beer was taken as a beverage. This dietary yielded about 3,680 calories a day. The effects were remarkably uniform. 3 Bread made from the 80 per cent. flour yielded for nutrition 96.1 per cent. of the energy contained in the diet; bread made from 90 per

1 "The Conservation of Wheat," Science, Vol. XLVII., No. 1218, p. 429; ScIEnce, N. S., Vol. XLVII., No. 1210, p. 228, March 8, 1918.

2 Copied from the J. Amer. Med. Assn., Vol. 70, No. 22, p. 1619, June 1, 1918.

3 The italics are my own. 